\title{
Comparison of the effects of IPS e.max heat press layered and feldspathic porcelain on natural enamel tooth wear
}

\author{
Hedaiat Moradpoor ${ }^{1}$, Marjan Mardanpour ${ }^{2}$, Farnoush Golmohamadi ${ }^{2}$ and Sahar Raissi ${ }^{3 *}$ \\ ${ }^{1}$ Assistant Professor, Prosthodontics Department, Faculty of Dentistry Kermanshah University of Medical \\ Sciences, Iran \\ ${ }^{2}$ Faculty of Dentistry, Kermanshah University of Medical Science, Kermanshah, Iran \\ ${ }^{3}$ Assistant Professor, Prosthodontics Department, Faculty of Dentistry Kermanshah University of Medical \\ Sciences, Iran
}

\begin{abstract}
In an ideal situation, the tooth wear of a restorative material should be similar to dental enamel. Currently, All-ceramic restorations are widely used; But Enamel wear is among the main disadvantages of ceramic restorations. Thus, in this study compared the Effect of IPS e.max heat press layered and Feldspathic Porcelain on natural enamel Tooth Wear.In this study, 20 samples were prepared from normal human teeth. The natural teeth were photographed by a stereomicroscope in a fixed position and the distance from the cusp tip to a reference point was measured. Next, 10 teeth opposed IPS e.max heat press layered and the remaining 10 opposed Feldspathic Porcelain in a chewing simulator and subjected to 120,000 masticatory cycles. The teeth were photographed again and the greatest difference between the before and after values was recorded. Finally data were analyzed by Independent samples T-test. The mean extent of wear on the restoration layered IPS e.max heat press and Feldspathic Porcelain were not significant differences ( $p$-value $=0.118$ ); although the average wear in Feldspathic Porcelain was less than layered IPS e.max heat press. the distance from the cusp tip to a reference point in layered IPS e.max heat Press was significantly difference between before and after intervention (p-value $<0.001)$. Also, the distance from the cusp tip to a reference point in FeldspathicPorcelain was significantly difference between before and after intervention ( $p$-value $<0.001$ ). According to the results obtained in vitro study, the mean extent of wear on the restoration layered IPS e.max heat press and Feldspathic Porcelain were not significant differences. Also, it is recommended to have a closer look at the factors involved in tooth enamel wear in future studies.
\end{abstract}

KEY WORDS: FELDSPATHIC PORCELAIN, IPS E.MAX HEAT PRESS LAYERED, ENAMEL TOOTH WEAR

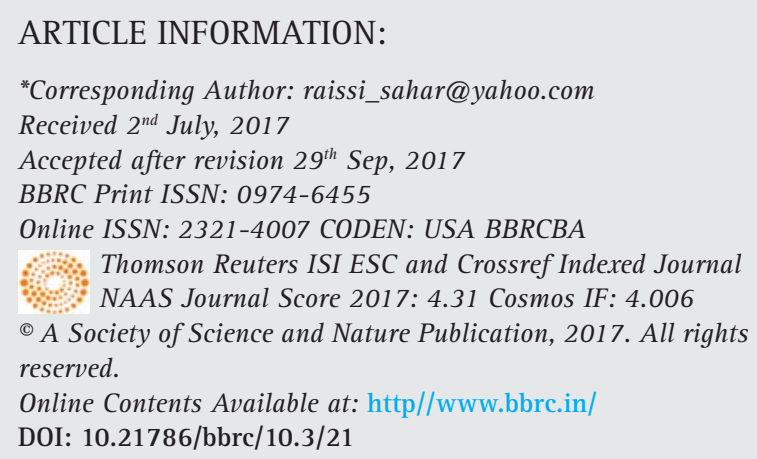




\section{INTRODUCTION}

Replacement of missing teeth or repair a part of a tooth has long been considered by dentists, Currently using a variety of ceramic restorations has largely resolved this problem; Ceramic restorations have advantages including lack of fracture, lack of blanching and high strength are also by considering the aesthetic, ease of use and color similar to natural tooth using these restorations have increased daily. These restorations due to the lack of metal in their structure (metal component can cause problems such as chemical toxicity, kerogen, change the color of gums and creating allergic reactions to some metals such as nickel) are preferred compared with coated of metal - ceramic (Jung 2010) and Rosenstiel, 2015, Murillo-Gómez, 2017 and (Montazerian, 2017).

There are also disadvantages in addition to the top benefits of these restorations that the most important of them is front tooth enamel erosion (Shillingburg, 2013). Erosion is defined as damage to the tooth surface or losing volume of teeth by direct contact with the teeth or other materials. In fact, erosion is a physiological phenomenon that is happening naturally always mechanically or chemically (DeGee, 1986). The sharp rise of dental erosion can cause to loss of centric contacts, vertical elevation change, Change in Functional paths during chewing and fusion muscle fatigue (DeLong, 1989) and (Gallegos, 1988). Dental restorations change the natural erosion rate of front teeth if have had different erosion features (Sulong, 1990). So erosion between tooth and its front restoration should be always considered as important factor along with strength and beauty to selecting restorative matter (Seghi, 1991).Considering this, various methods have been tested to improve and reduce the erosion of the front teeth in ceramicrestorations; Among these methods, reinforced ceramics with alumina oxide crystals, Lusaite, lithium DE silicate and zirconia (Komine, 2004) and (Barath, 2003).

Given the importance of the front dental erosion by ceramic restoration, in this study, two restorations of the Feld spathic porcelain and layered IPS e.max heat press ceramic were evaluated and compared in terms of the front side tooth enamel. The reasons for choosing these two restorations can be reffered to improve the ceramic properties and porcelain bonding systems that has been caused to beauty and good performance of feldspathic porcelain (Vieira, 2004) and IPS e.max Press makers claim to improve physical and translucency properties, lower surface hardness low concentrations of crystalline phase and a smaller sizes of crystals at different stages of cooking Empress 2 and revise in formulation of the this kind of ceramic to obtaining high quality (Newsome 2014) and (Guess 2011).

Of course in laboratory studies that have been done in this area, a significant difference has not been specified in phase composition and the bending strength between IPS e.max Press and Empress 2 (Guazzato, 2004) and (Albakry 2003). IPS e.max Press in monolithic mode is used for inlays, onlays, full coverage of crown... (Guess 2011). In times of short and medium term have shown in reviewing these performances that IPS e.max Press restorations have good performance: Using this restoration in onlays in the 3-year period, the efficiency of $100 \%$ (Guess 2009) and the crown in the 3-year period has had the performance of 96.6\% (Etman, 2008). Despite this high performance, high erosion possibility of this restoration on the tooth enamel can be considered as one of the major disadvantages (Esquivel-Upshaw 2012). Also, amount of natural tooth erosion against the layered IPS-emax heat press and feldspathic porcelain were discussed due to lower researches and lack of consensus on the abrasive effect of these ceramics and the need for further studies in this area.

\section{MATERIALS AND METHODS}

This study was done as In vitro and in Reference Laboratory and Research Center University of Medical Sciences in Tehran. The study population was healthy teeth recently extracted and without premolar decay of human maxillary. Easy non-probability sampling method and sample size were obtained from the results of previous studies (Ahmadzadeh, 2014) and by considering $\alpha=0.05$, and power of $1-\beta=80 \%$, at least 20 teeth. Trend of running in this study was in this way that in each group 10 samples were prepared with dimensions of $10 \times 10 \times$ $10 \mathrm{~mm}$. in IPS-emax heat press group in order to build cylinders of a block with cross-section dimensions $10 \times$ $10 \times 10$ is molded with incremental silicone impression material and then wax blocks were prepared by melting the inlay10 wax. Then these wax blocks, were done sprue, cylindering and were cast by vita ceramic Inge. Specific cylinder device: Chewing simulator (CS-4.2 S / $\mathrm{N}$ : A100220128SM01) was used to cylindering (Figure 1).

Cylinder was heated to $800{ }^{\circ} \mathrm{C}$ under to evaporate and remove the wax pattern. Vita ceramic ingot was placed within the cylinder by tongs and cylinder was placed in specific furnaces. After warming oven to temperature of $920^{\circ} \mathrm{C}$, ceramic melted slowly and in vacuum was injected into the cylinder.Sprue cut off and the samples were sandblasted by 2-1 times of aluminum oxide after cooling cylinder. Then the blocks were drool with powder and liquid of VitaAkzent Plus .wax blocks was used to make Feldspathic porcelain with dimensions $10 \times 10 \times 8 \mathrm{~mm}$ has been molded with an incremental silicone impression material and then wax blocks were prepared by melting the inlay 10 wax. Then these blocks were done sprue and cylindered and were cast by Vero bond (vita mark) alloy. 
Porcelaining was done with VMK master (vita mark) porcelain by thickness of $2 \mathrm{~mm}$ and external dimensions were measured by a gauge after cutting the sprue and sandblasting and grinding alloy with pink and white stone. Premolar healthy natural teeth of 4 human maxillary as well as were selected to the total number of samples and were stored in distilled water until erosion time. all samples were mounted by Survivor in a plastic mold in the shape of a half-cylinder in-hardening resin (Ivoclarvivadent) before testing. Then the photos were taken of dental teeth in Razi Metallurgical Research Center (Razi Metallurgical Research Center) by stereomicroscope (VEGA II TESCAN) in fixed position and a fixed place was determined for each sample. Distance from the cusps tip to the desired location was measured by the Motic Image Plus software. Then natural teeth were placed in the front samples of feldspathic porcelain and layered ips-emax heat press in chewing simulator device. The samples were immersed in distilled water at all times of erosion. After the erosion test, the photos were taken of samples by stereomicroscope again in the same previous position and due to mentioned method the measurement was done for each cusp again; the difference between the two amounts was recorded and the highest was recorded per micrometer. Data with SPSS software version 18 and by using statistical analysis Independent samples $\mathrm{T}$ test were used for statistical analysis. The significant level of 0.05 was considered in this study.

\section{RESULTS AND DISCUSSION}

In this study, with the help of Shapiro-Wilk test it was determined that the data are followed from a normal distribution (0.05 <p-value). Means of erosion rate between the two materials of layered IPS e.max heat press and Feldspathic Porcelain was evaluated by independent samples t-test and erosion difference between the two restoration was not statistically significant ( $p$-value $=0.118$ ) although the mean of erosion rate in Feldspathic Porcelain was less than layered IPS e.max heat press (table 1).

As it is shown in Table 1; paired t-test showed that the difference between the mean difference of the vertical height of the tip of the buccal cusps to central fossa in tooth surface in IPS e.max heat press between before and after the intervention (0.001> p-value) and in Feldspathic Porcelain between before and after the intervention (0.001> p-value) was significant.

\section{DISCUSSION}

Ceramic materials made with respect to stiffness and strength of them are usually resistant to erosion, but erosion tighter than usual their front teeth is what is made problem in this type of restorations (Heintze, 2008). In the present study, there was no statistically significant difference between the mean of erosion rate in two restorations of layered IPS e.max heat press and Feldspathic Porcelain (0.118 = p-value), although mean of erosion rate in Feldspathic Porcelain somewhat was lower than layered IPS e.max the heat press.

In a study by Tian et al. (2013) that the erosion rate of two groups of Porcelain Ceramics, and layered IPS e.max heat press were studied, the results showed that the erosion rate on in the layered IPS e.max heat press ceramic has been much more than Porcelain (Tian, B.M 2013) which is inconsistent with results of this study. In a study of Esquivel-Upshaw the rate of Front tooth

\begin{tabular}{|c|c|c|c|c|c|c|c|}
\hline \multicolumn{2}{|l|}{ Wear rate } & \multirow[t]{2}{*}{$p$-value ${ }^{\mathrm{a}}$} & \multicolumn{2}{|c|}{$\begin{array}{l}\text { The vertical height of the buccal } \\
\text { cusp tip of the tooth surface after } \\
\text { the intervention of the central } \\
\text { Tafusay }\end{array}$} & \multicolumn{2}{|c|}{$\begin{array}{l}\text { The vertical height of the buccal } \\
\text { cusp tip of the tooth surface } \\
\text { before the intervention of the } \\
\text { central Tafusay }\end{array}$} & \\
\hline $\begin{array}{l}\text { Standard } \\
\text { deviation }\end{array}$ & Average & & Standard deviation & Average & $\begin{array}{l}\text { Standard } \\
\text { deviation }\end{array}$ & Average & \\
\hline $0 / 0673$ & $0 / 6849$ & $<0 / 001$ & $0 / 3506$ & $1 / 9141$ & $0 / 3482$ & $2 / 5990$ & $\begin{array}{l}\text { layered IPS } \\
\text { e.max heat } \\
\text { press }\end{array}$ \\
\hline $0 / 1731$ & $0 / 5859$ & $<0 / 001$ & $0 / 4596$ & $1 / 6656$ & $0 / 4769$ & $2 / 2515$ & $\begin{array}{l}\text { Feldspathic } \\
\text { Porcelain }\end{array}$ \\
\hline \multicolumn{2}{|l|}{$0 / 118$} & & \multicolumn{2}{|l|}{$0 / 191$} & \multicolumn{2}{|l|}{ 0/079 } & $p$-value ${ }^{\mathrm{b}}$ \\
\hline
\end{tabular}




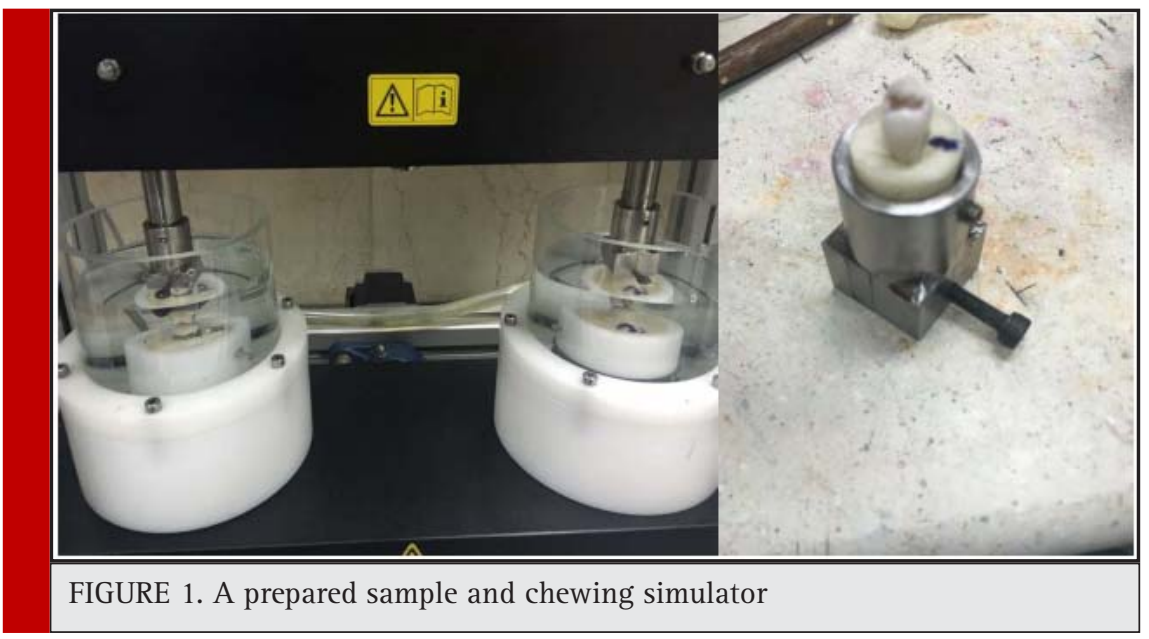

enamel erosion has been reported by restoration of IPS e.max heat press $\mu \mathrm{m} \mathrm{88/3}$ (Esquivel-Upshaw 2012). in study of Etman, et al that also studied the erosion of Front tooth enamel in three types of ceramic restorations, the results showed that after two years of following the erosion mean created by Allceram Procera, $\mu \mathrm{m}$ 261, has been for IPS e.max heat press $\mu \mathrm{m} 215$ and metal ceramics $\mu \mathrm{m} 156$ that this difference was statistically significant (Etman, 2008).

In this study, Means of vertical height of the tip of the buccal cusps to central fossa in tooth surface after the intervention there was no significant difference between the two materials ( $p$-value $=0.191$ ); But vertical height means of the tip of the buccal cusps to central fossa tooth surface on the material of layered IPS e.max heat press there was a statistically significant difference between before and after the intervention (0.001> p-value) and in Feldspathic Porcelain between before and after the intervention (0.001> p -value). It is clear that the significant erosion has occurred with regard to these results. But the erosion differences have not shown obvious difference between two restorations. Heintze et al. by examining erosion rate of front ceramic teeth and factors affecting on it, have recognized that factors such as the shape of the samples, surface treatment, enamel thickness, type of milling device and its geometry shape, grains size and crystal size are effective in erosion (Heintze, 2008).

In fact, the erosion is related to the friction created between the two levels, so it can be concluded that surface properties and conducted interaction will have important impact by contact in the two levels. Smooth surfaces have less resistance and therefore less erosion compared to uneven surfaces; the erosion rate of them on front teeth will be also more whatever the surface roughness of restorative materials to be more. For this reason, it has always tried to maintain the strength of the restoration; its surface roughness is reduced as much as possible. According to studies conducted, the surface roughness is for feldspathic porcelains of MPa 6560 and for IPS e.max Press, MPa 5800 that due to the proximity of value of this variable in two restorations examined, lake of difference in Front tooth erosion is also justified (Al-Shehri 2002).

Another important factor in front tooth erosion fracture toughness. All ceramic materials that have been used in dentistry so far, has been with much lower fracture toughness than metals. According to studies for fracture toughness of IPS e.max Press MPam 1/22/ 1- 4/3 (14) and for feldspathic porcelain on range of MPam 1/290/0 up to be 1.56 (23), as well as natural tooth enamel fracture toughness has been reported in the range of MPam 1/237/1-7/0 (Heintze, S.D 2008) and natural teeth dentin has been reported in MPam 1/208/3 (24), that compared with metals have less fracture toughness between 20 and 100 times. Lee et al in New Zealand during a study have shown that gold brigade 3 compared to IPS e.max Press has less abrasive and friction on the tooth enamel and can be seen significant cracks in front enamel surface of samples of IPSe.max Press examples in comparison with gold brigade 3 (Lee 2012). Lee and et al differences in fracture toughness in different materials know as one of the Justifier factor; so that during the action and the inclusion of occlusal forces on the surface of the restoration are with micro fracture and lead to bumps and abuses such as inclusion Crystalline that are going off the surface of the material; as result leads to accumulation of a lot of pressure on enamel and troughs Gauging. In addition dug particles can act like an Abrasive and to create three-dimensional erosion; So it can be expected that less erosion is created in front teeth in the restorations with higher fracture toughness (Anusavice, 2013). Given that in terms of fracture toughness as well as there was no significant differences between two 
restorations evaluated in this study, so the same Front tooth erosion is justifiable.

\section{CONCLUSION}

According to the results obtained in present experimental study, the means of erosion rate in two restorations of layered IPS e.max heat press and Feldspathic Porcelain has no statistically significant difference with each other, although mean of erosion rate in the Feldspathic Porcelain has been somewhat lower than layered IPS e.max heat the press; The results showed that the erosion on both the restorations after intervention has been significant compared to before intervention; As a result, it can be concluded that these two restorations causes to significant erosion of front tooth enamel, but have no significant difference with each other.

\section{SUGGESTIONS}

It is suggested that in future research erosion caused be evaluated by natural tooth enamel and other high applicable restorations and also be compared by two restorations of layered IPS e.max heat press and Feldspathic Porcelain. It is also possible to design and carry out long-term laboratory studies of this kind, to provide the information necessary to assess the relationship between laboratory and clinical erosion data.

\section{REFERENCES}

Ahmadzadeh, A., Ashtiani, A.H., Epakchi, S., Pormehdi, M., Neshati, A., Golmohamadi, F. and Mousavi, N., 2014. Comparison of the Effect of Feldspathic Porcelain and Zirconia on Natural Tooth Wear. Journal of Islamic Dental Association of IRAN (JIDAI), 26(3), p.3.

Albakry, M., Guazzato, M. and Swain, M.V., 2003. Fracture toughness and hardness evaluation of three pressable allceramic dental materials. Journal of dentistry, 31(3), pp.181188.

Al-Shehri, S., 2002. Relative fracture toughness and hardness of dental ceramics. Saudi Dent J, 14(2), p.67.

Anusavice, K.J., Shen, C. and Rawls, H.R., 2013. Phillips' science of dental materials. Elsevier Health Sciences.

Barath, V.S., Faber, F.J., Westland, S. and Niedermeier, W., 2003. Spectrophotometric analysis of all-ceramic materials and their interaction with luting agents and different backgrounds. Advances in Dental Research, 17(1), pp.55-60.

DeGee, A.J., Pallav, P. and Davidson, C.L., 1986. Effect of abrasion medium on wear of stress-bearing composites and amalgam in vitro. Journal of Dental Research, 65(5), pp.654-658.

DeLong, R., Sasik, C., Pintado, M.R. and Douglas, W.H., 1989. The wear of enamel when opposed by ceramic systems. Dental Materials, 5(4), pp.266-271.
El Mowafy, O.M. and Watts, D.C., 1986. Fracture toughness of human dentin. Journal of dental research, 65(5), pp.677-681.

Esquivel-Upshaw, J.F., Rose, W.F., Barrett, A.A., Oliveira, E.R., Yang, M.C., Clark, A.E. and Anusavice, K.J., 2012. Three years in vivo wear: core-ceramic, veneers, and enamel antagonists. Dental Materials, 28(6), pp.615-621.

Etman, M.K., Woolford, M. and Dunne, S., 2008. Quantitative measurement of tooth and ceramic wear: in vivo study. International Journal of Prosthodontics, 21(3).

Gallegos, L.I. and Nicholls, J.I., 1988. In vitro two-body wear of three veneering resins. The Journal of prosthetic dentistry, 60(2), pp.172-178.

Guazzato, M., Proos, K., Quach, L. and Swain, M.V., 2004. Strength, reliability and mode of fracture of bilayered porcelain/zirconia (Y-TZP) dental ceramics. Biomaterials, 25(20), pp.5045-5052.

Guess, P.C., Schultheis, S., Bonfante, E.A., Coelho, P.G., Ferencz, J.L. and Silva, N.R., 2011. All-ceramic systems: laboratory and clinical performance. Dental Clinics of North America, 55(2), pp.333-352.

Guess, P.C., Strub, J.R., Steinhart, N., Wolkewitz, M. and Stappert, C.F., 2009. All-ceramic partial coverage restorationsmidterm results of a 5-year prospective clinical splitmouth study. journal of dentistry, 37(8), pp.627-637.

Heintze, S.D., Cavalleri, A., Forjanic, M., Zellweger, G. and Rousson, V., 2008. Wear of ceramic and antagonist-a systematic evaluation of influencing factors in vitro. dental materials, 24(4), pp.433-449.

Jung, Y.S., Lee, J.W., Choi, Y.J., Ahn, J.S., Shin, S.W. and Huh, J.B., 2010. A study on the in-vitro wear of the natural tooth structure by opposing zirconia or dental porcelain. The journal of advanced prosthodontics, 2(3), pp.111-115.

Komine, F., Tomic, M., Gerds, T. and Strub, J.R., 2004. Influence of different adhesive resin cements on the fracture strength of aluminum oxide ceramic posterior crowns. The Journal of prosthetic dentistry, 92(4), pp.359-364.

Lee, A., 2012. Wear behaviour of human enamel opposing lithium disilicate glass ceramic and type III gold (Doctoral dissertation, University of Otago).

Montazerian, M. and Zanotto, E.D., 2017. Restorative Dental Glass-Ceramics: Current Status and Trends. In Clinical Applications of Biomaterials (pp. 313-336). Springer International Publishing.

Morena, R., Lockwood, P.E. and Fairhurst, C.W., 1986. Fracture toughness of commercial dental porcelains. Dental Materials, 2(2), pp.58-62.

Murillo-Gómez, F., Rueggeberg, F.A. and De Goes, M.F., 2017. Short-and Long-Term Bond Strength Between Resin Cement and Glass-Ceramic Using a Silane-Containing Universal Adhesive. Operative Dentistry.

Newsome, P., 2014. Use of ceramic materials in the restoration of posterior teeth. Primary dental journal, 3(2), p.42.

Rosenstiel, S.F., Land, M.F. and Fujimoto, J., 2015. Contemporary Fixed Prosthodontics-E-Book. Elsevier Health Sciences. 
Seghi, R.R., Rosenstiel, S.F. and Bauer, P., 1991. Abrasion of human enamel by different dental ceramics in vitro. Journal of dental research, 70(3), pp.221-225.

Shillingburg, H.T., Sather, D.A., Wilson, E.L., Cain, J.R., Mitchell, D.L., Blanco, L.J. and Kessler, J.C., 2013. Fundamentals of fixed prosthodontics. Acta stomatol Croat, 47(2), p.177.

Sulong, M.Z.A.M. and Aziz, R.A., 1990. Wear of materials used in dentistry: a review of the literature. The Journal of prosthetic dentistry, 63(3), pp.342-349.
Tian, B.M., Zhang, S.F., He, L., Guo, J.W., Yu, J.T. and Wu, X.H., 2013. An experimental study of the wear behavior of dental feldspathic glass-ceramic and lithium disilicate glass-ceramic. Zhonghua kou qiang yi xue za $\mathrm{zhi}=$ Zhonghua kouqiang yixue zazhi $=$ Chinese journal of stomatology, 48(11), pp.683688.

Vieira, L.C.C., Araújo, É. and Monteiro Júnior, S., 2004. Effect of different ceramic surface treatments on resin microtensile bond strength. Journal of Prosthodontics, 13(1), pp.28-35. 